\title{
Saudi Educators' Perspectives on the Reggio Emilia Approach
}

\author{
Ghadah Alsedrani \\ Assistant Professor in Early Childhood Education \\ Collage of Education \\ King Saud University \\ Saudi Arabia
}

\begin{abstract}
The purpose of this study, which is based on my PhD dissertation (Alsedrani, 2018), is to describe, explain, and analyze teachers', supervisors', and educational administrators' perspectives about the challenges and benefits of adopting the Reggio Emilia approach (REA) into early childhood institutions in Saudi Arabia (SA).Early childhood education (ECE)faces many challenges in SA. Thus the researcher argues that implementing the REA in Saudi kindergartens may help overcome some of the challenges that are confronting ECE in SA today. This study used indepth, semi-structured interviews to explore and analyze ECE educators' perspectives about implementing the REA into Saudi ECE. Data were analyzed using the constant comparative analysis approach; to explore the participants' opinions about the likelihood of implementing the REA, what it would take to adopt, and how it could be modified to fit the social, cultural, and religious contexts in SA.
\end{abstract}

Keywords: early childhood education, Saudi kindergarten teachers and administrators, Reggio Emilia Approach.

Saudi Vision 2030 has several economic, social, and educational goals. As it relates to early childhood education (ECE), Vision 2030 focuses on developing the ECE curriculum, improving teacher preparation and development programs, enhancing creativity and innovation in the learning environment, improving students' skills and values, and encouraging the private sector to invest in ECE by funding new kindergartens, preschools, and daycare centers (Saudi Vision 2030 2016; Mosaad 2016; Patalong 2017).

As ECE in Saudi Arabia (SA) continues toward achieving the Vision 2030 goals, it has encountered several obstacles that may hinder the effectiveness of children's learning experiences. Several researchers have examined the current ECE program, its shortcomings and problems (Alhamed and Zyadh 2007; Aljabreen and Lash 2016). These include the current guiding ECE philosophy, practices, and objectives, the lack of adequate teacher preparation, insufficient financial support, and the total dependence on and direction from a central administrationthe Saudi Ministry of Education. Moreover, up-to-date technology is often not available in ECE classrooms (Alhamed and Zyadh 2007). Areas in need of urgent attention include the traditional teacher-centered model of education, the standardized self-learning curricula, the lack of collaboration with parents, families, and the community, the use of a centralized education management model, and the image of the child as a passive learner (Metwaly 2007). As long as these remain unaddressed and unchanged, they will continue to obstruct the ministry's efforts to improve ECE in SA (Metwaly 2007).

In this study, I was guided by the following research question: What are the potential challenges and benefits of adopting the REA in ECE in Saudi Arabia? For this reason, I describe, explain, and analyze the perspectives of teachers, supervisors, and educational administrators about this question. In my opinion, the REA could address many of the challenges that currently hinder the effectiveness of Saudi ECE and its progress toward achieving the goals in Vision 2030.

\section{Early Childhood Education Objectives}

After 1980, the ECE curriculum in SA began to be structured and directed by the national Ministry of Education in an effort to improve the level of children's intellectual development and to ensure the national curriculum was divided into "age-appropriate objectives" (Aljabreen and Lash 2016, 315). Drawn from Piaget's (1973) theory of cognitive development, Saudi educators, who designed the national kindergarten curriculum for its public and private schools, believed that three- to six-year-olds learn best when interacting with the environment around them. The curriculum encourages expression through verbal and nonverbal methods-drawing, building, acting, designing-while learning from signs, stories, songs, and the like (Hwasheen and Hwasheen 2008). This developmental perspective of learning was revolutionary, but it did not address the effect of social interaction with teachers and peers on learning at this age. The national, standardized curriculum and directives to teachers stressed the importance of providing young children with the freedom to express themselves in diverse ways that did not conflict with the religious and social culture. 


\section{Lack of Collaboration between Family and School}

Saudi kindergarten teachers conduct an annual conference with each student's mother (Saudi Ministry of Education [SME]2005/2006). Teachers also invite each mother at least once a year to visit the classroom and participate in a program called "the Visiting Mother" (SME 2005/2006). However, from my observations, mothers often use these visits as a chance to distribute gifts to the other children in the class, remaining for only a short time and foregoing the primary purpose - to become involved in class activities.

But the larger problem is that families do not believe that school-family collaboration and volunteering in school activities is important (SME 2006). According to Alageel (2005), many parents think their role ends when they pay the tuition. He wrote that 83.3 percent of the principals, 100 percent of the school staff, and 82.3 percent of the teachers reported that the majority of mothers do not visit unless the principal or the teacher personally invites them.

\section{Early Childhood Teacher Preparation}

In 1983, the Gulf Girl Association in SA established an ECE teacher preparation program and offered educational degrees to women wishing to specialize in ECE (Aljabreen and Lash 2016). The program included a curriculum based on educational theory and practice, and mandated the completion of sixty-four credits, "including significant time with a full-time teacher-mentor in a preschool" (Abduljawad et al. 2008, as cited in Aljabreen and Lash 2016, 316). I worked as a teacher-trainer in this program for more than ten years. Teacher-trainers supervised the student teachers in private kindergarten settings three days a week for an academic year. Other universities and colleges in large cities now provide a variety of ECE teacher training programs (Aljabreen and Lash, 2016). However, from my experience and the feedback I received, student-teachers entering the teaching environment continue to find a large gap between what they learn in training programs and what they observe in classrooms. The harsh reality is that children's behavior and classroom management are a significant challenge to inexperienced ECE teachers.

Several studies have identified some practical obstacles related to newly trained and hired ECE teachers. One is the lack of qualified, experienced ECE teachers within these kindergartens (Alotaibi and Alsewilem 2002). Many teachers trained under the lax ECE teaching requirements that existed before the early to mid-1980s. Moreover, preschool teachers show little desire for more training because overcrowded classrooms are the norm in SA, presenting teachers with more behavioral control issues rather than issues related to effective lesson planning, for instance. The government offers few financial or professional incentives to teachers to obtain more training (Aldham 2012; Bakari2012), and there are not enough course offerings (Bakari 2012).

\section{The Legal Organization of the Saudi Educational System}

The private ECE sector and two government bureaucracies - the Ministry of Education and the Ministry of Labor and Social Affairs - supervise and manage public and private kindergartens in SA (Al-Madkhaly 2014). That the organization and control of ECE lies in the hands of a national ministry presents advantages and disadvantages. On the one hand, educational unity and centralized management can ensure all kindergartens employ the same basic educational philosophy and priorities throughout SA. Such centralization helps ensure that children engage with rich, various, and renewable materials and activities, even in small cities. In addition, a single, national curriculum helps teachers focus on achieving its objectives most effectively. A unified curriculum also serves to prevent inappropriate decisions by outlier ECE institutions (Alotaibi and Alsewilem 2002). On the other hand, such centralization causes weaknesses in the efficiency of its administrative system because of a dependence upon bureaucracy and routine. Bureaucracies often resist change, so reforms then become more difficult to propose or enact, even when such changes would benefit the national educational system (Alotaibi 2008).

\section{The Weak Management in Private Kindergartens}

The private sector initiated and still dominates Saudi ECE (Al-Madkhaly 2014; Alotaibi and Alsewilem 2002). The owners of many of these schools see them primarily as investments to provide profits (Aljabreen and Lash 2016). For this reason, these schools can charge higher tuition fees while lowering salaries for the teachers and other staff, resulting in less-qualified, less-competent teachers (2016). To increase the teaching quality, the ECE department in the ministry has recently mandated that private ECE institutions cannot hire teachers who have not specialized in ECE. In addition, private kindergartens are often poorly managed; they fail to hire teachers and administrators with experience and expertise. Instead, they hire lower-paid, non-educational administrative teams to manage and operate them. Such mismanagement and disorganization affect teacher morale and children's scholastic achievement and can result in bankruptcy and school closings (Alhamed and Zyadh 2007; Metwaly 2007).

\section{An Overview of the Reggio Emilia Approach}

Reggio Emilia is a town in northern Italy renowned for its unusual post-World War II approach to education (Cagliari et al. 2016; Nelson 2000). 
The REA asserted that social services and education were inseparably linked (Cagliari et al. 2016; Edwards, Gandini, and Forman 2012); both components were necessary to teach children most effectively (Gandini 1993).

The child was placed directly at the center, viewed as hungry for knowledge and active in their own learning, rather than as the blank slate of old (Hewett 2001; Lindsay 2015). Educators came to view and value children as powerful, resilient, talented, insatiably curious, and capable of finding their place in the world (Edwards, Gandini, and Forman2012).

The REA lends itself to assimilation by different social and cultural contexts (Inan 2009). "No two schools will ever be alike; what works for [one] Reggio Emilia preschool will not necessarily work for another Reggio school" (Inan 2009, 9). Each school applies its own version of the REA to their children's interests and specific needs in harmony with that specific community's social and cultural contexts (Alnageeb 2009; Inan 2009). This new approach to kindergarten education proved to be quite successful (Alnageeb 2009; Alshawareb 2012). As of four years ago, Edwards, Gandini, and Forman (2012) identified more than thirty municipals RE preschools and kindergartens for children under six that have sprung up in Italy since 1963 (Dodd-Nufrio 2011).

\section{The Core Principles of the Reggio Emilia Approach}

According to Gandini $(1993,5)$, the fundamental ideas of the REA are "tightly connected, in which each point influences and is influenced by all the others." These core principles need to be wholly adopted to reap the benefits (Cagliari et al. 2016). It can easily be customized to meet the adopting school's needs and their particular cultural mores or religious ideals, but its central principles must be adopted and implemented (Alnageeb 2009; Inan 2009).

\section{The image of the child}

Malaguzzi (2012), a principal founder of the REA, stated that

All people — and I mean scholars, researchers, and teachers, who ... s study children seriously — have ended up by discovering not ... the limits and weaknesses of children but rather their surprising and extraordinary strengths and capabilities linked with an inexhaustible need for expression and realization. (Edwards, Gandini, and Forman 2012, 53)

A guiding principle is that children are powerful and competent, able to teach each other, their teachers, and parents, and learn from their environment (Nelson 2000). Malaguzzi explained this does not simply refer to the competent child, but also to the child as creator and the co-creator of the curriculum, entitled to the same human rights accorded to adults, while also needing protection and support (Cagliari et al. 2016).

\section{The hundred languages of children}

The REA provides various ways of learning tailored to each child's particular interests (Eckhoffand Spearman 2009; Tarr 2004). It strongly encourages the use of many different modes of expression besides teacher-talk, such as the use of symbols or pictures, art and drawings, games, words, music, and movement - to name just a few of what are collectively termed "the hundred languages of children" (Edwards, Gandini, and Forman 2012,10).

\section{The role of teachers as co-learners and partners}

The REA positions teachers as students' partners in learning and discovery (Lindsay 2015). They facilitate rather than control discussions. Often, they walk away from that experience having learned as much as their students. In the REA, learning is a collaborative relationship between students and teachers (Cagliari et al. 2016). The two teachers in each RE classroom play their central roles as sounding boards or guides, leading students to new insights based on their personal experiences, always ready to intervene by "providing the child with the provocations and tools necessary to achieve [their] goals . . . and by providing scaffolding to assist children in their learning and consequent development" (Hewett 2001, 97). The RE teacher comes to know the students as individuals on their unique learning journeys that unfold over time (Valentine 2006).

$\mathrm{RE}$ classrooms are unique for many reasons. Each classroom is assigned two teachers; each is required to invest thirty-six hours per week, most of it actively spent with students, with four to five hours a week for meetings with fellow teachers (Rinaldi 1994) or to receive on-the- job, "in-service training" (Palestis1994, 17). The two teachers work as partners with the same group of students for the three years the children spend at RE kindergartens (Rinaldi 1994). Among other benefits, it presents the opportunity to observe the same children "from different points of view" and be a part of the extraordinary growth and development children experience in those three years (1994, 56). 


\section{Documentation}

Cagliari et al. (2016) explained that documenting children's activities is not only for record keeping, but to help teachers evaluate the effectiveness of their lessons and interventions in the learning process. It also involves parents by giving them the opportunity to watch their child's school activities (Staley1998).

It gives teachers material to exchange, compare, and discuss. Importantly, it creates a record of the child's accomplishments, and can inspire discussion among the students and between students and teachers (Nelson 2000).

\section{The classroom and the emergent curriculum}

The REA encourages students to shape their own curricula (Nelson 2000). Student discussions among themselves and with teachers helps teachers discover ways to facilitate a particular activity or teach a unit or lesson (Hewett2001). If a certain topic is especially interesting to the students, teachers can devote as much time as they wish on it (Hewett 2001). Without a prescribed curriculum, children can set their own pace and take the learning experience in whichever direction they want under the close observation and facilitation of the teachers(Nelson 2000).

\section{Projects}

The REA values the power of projects to help children learn through experience and problem-solving (Cagliari et al. 2016; Wurm 2005). In RE kindergartens, the child is seen as a social being with the freedom to explore their surroundings. Class, group, or individual projects encourage such explorations (Cagliari et al., 2016; Edwards, Gandini, and Forman 2012). Projects allow students to include as many stages as possible into lessons and provides an opportunity to observe and explore the topics of the project, formulate hypotheses, and discuss related issues for as long as they feel it is necessary (Cagliari et al. 2016; Hewett 2001).

\section{The clock does not set the time}

In the REA, teacher relationships with students are preserved from year to year, which provides the teachers with data that help determine how much time the class should spend on a given topic (Edwards, Gandini, and Forman 2012). Educators are free to design a loose all-day schedule for their students, while still ensuring they never run out of potential learning activities (Nelson 2000).

\section{The environment as the third teacher}

The environment surrounding children is related to what and how much is learned (Strong-Wilson and Ellis 2009). In RE, the environment plays such an important role that it has been referred to as "the third teacher" (StrongWilson and Ellis 2009, 40; Nelson 2000, 16; New 2009, 8). The classroom should remain flexible and fluid so that it can be rearranged to meet the needs of diverse educational activities and create a stage more likely to stimulate children's innate curiosity and desire to learn (Firlik 1994).

\section{The role of parental and community involvement}

The REA encourages collaboration between parents and teachers to maximize the impact of student learning (Nelson 2000). This collaboration takes many forms: assisting with lessons and activities, discussing school policy, or visiting the classroom (Wurm 2005). Parents are strongly encouraged help plan and accompany the class on field trips (Wurm 2005). Some researchers argue this should also involve the community (Cagliari et al. 2016; Lindsay 2015), and family and community members are encouraged to help organize special events at kindergartens (Wurm 2005).

\section{Study Setting and Sites}

The three settings for data collection were public and private kindergartens in each of Riyadh's nine school districts, ECE departments in the nine district administration buildings, and the General Management Office for Kindergartens in the Saudi Ministry of Education.

\section{Participant Sampling Strategy}

The study's sample consisted of twenty-two participants: one ECE teacher and one ECE supervisor from each of the nine Riyadh districts, and four kindergarten administrators from the Ministry of Education's ECE department.

Two to four days before I conducted an interview, each teacher received a handout describing the REA's historical beginnings in Italy, its theoretical orientation, and fundamental principles. In addition, I provided extra resources, book titles, hyperlinks to useful RE sites, my contact information in Arabic, an introductory video presentation about the REA in ECE, a hyperlink to the RE's video, and electronic copies of the handout to participants. 


\section{Data Collection Methods}

I used several data collection methods: in-depth, face-to-face, semi-structured interviews of twenty-two teachers, supervisors, and educational administrators, and structured walking interviews through kindergarten buildings with teachers that allowed me to investigate how ECE teachers understand and engage with their classrooms and the school's environment (Evans and Jones 2011).

I also included analytic memos and other documents as secondary data sources that included ministry policies, organizational guides, ECE learning standards, the ministry's guide for the self-learning curriculum, lesson plans, and photographs of the schools and classrooms.

\section{Analytical Framework and Data Interpretation}

I used the REA's six core principles as a priori categories (child's role in the learning process, documentation and assessment processes, classroom environment, emergent ECE curriculum, teacher role, and school-family collaboration) and then used constant comparative analyses within those categories relative to participants' responses. Topic analysis allowed me to create a thread among themes and events, one that could be used to form the basic outlines of a model (Labov 1972, as cited in Bamberg 2010). In addition, I identified codes and categories that fell outside these six core principles and included them in the resulting model. For instance, the time and schedule category was combined with the physical environment category.

\section{Discussion and Conclusions}

The research question for this study was the following: What are the potential challenges and benefits of adopting the Reggio Emilia Approach in ECE in Saudi Arabia? In this section I discuss key findings and comparatively analyze ECE in SA and the REA according to six elements (or themes) important in any comprehensive educational reform: the child's role in the learning process, the documentation and assessment processes, the classroom environment, the emergent ECE curriculum, the role of the teacher, and the nature of school-family collaboration. In addition, I present some recommendations to improve current ECE policies and practices, suggestions that may lead to a successful integration of the REA in Saudi ECE.

I argue that Saudi ECE should adopt the REA because it provides children with the following: (a) learning experiences from multiple information sources through projects; (b) a positive image of themselves as learners and partners in designing and implementing their learning experiences; (c) teachers that perform multiple, facilitative roles and view students as active learners able to construct their own knowledge; (d) assessments through teacher documentation of the child's developmental achievements, rather than in comparison to national student achievement data and fixed, general criteria for successful learning; (e) interactions with rich, attractive natural environments; and (f) many opportunities for family and local communities to participate in their children's education (Wurm 2005). Currently, these elements are either lacking or nonexistent in Saudi ECE.

\section{Top-Down or Bottom-Up?}

Current ECE orientation in SA is top-down. Teachers must follow prescribed lesson plans designed by the central ministry and taught according to a fixed schedule with every child assessed at the termination of the learning unit. Saudi teachers cannot alter the teaching plan in any meaningful way. As supervisor S.AR. told me, "She [the teacher] does not have any power. We [supervisors] tell her that she is in the position of being the decision maker, but we lied. We lied to ourselves and to her. I was a teacher, and I could not do anything" (personal communication, December 13, 2017).E.A., a private kindergarten teacher, added that if you read the units book and the teacher's guidebook . . . it is mentioned that teachers have the freedom to make any modification that suits the children's situations. So, she has the freedom. But with the supervisory authority overseeing her? You can forget this point. The supervisors ask the teachers to follow the curriculum plans exactly. That is not right because children, backgrounds, and cultures are different. Where is her role as a teacher to adjust the learning objectives to the children's needs? Children have to be the engines that formulate the learning process and its goals. (E.A., personal communication, August 20, 2017)

In contrast, the RE philosophy is considered a "bottom-up practice" (Lewin-Benham 2011, 14). Children decide with their teachers what to learn throughout a flexibly scheduled, open-ended day. Children design their own learning experiences and are then held responsible. In my opinion, this would require a major reevaluation by ECE educators of how young children learn most effectively. Gaining a fuller, practical understanding of this major difference and its effect on theory, policy, and practice may help educators more critically evaluate the possibilities of implementing the REA in the Saudi context.

\section{Recommendations for ECE Policy and Practice Reform and Adoption of the REA}

Saudi ECE has much to gain from a comprehensive examination of the REA. It begins with changing the view of children as passive learners to one that regards children as active participants in learning. Any significant reform in 
this direction will require a revised education and training program for teachers and major realignments in system management. However, educators I interviewed realize that adopting a new approach is difficult in the beginning. It can collide with the community's educational orientation, philosophy, and beliefs. Thus, steady, gradual change in this direction would help build a better ECE system.

\section{Give the child's curiosity and interest a lead in planning and designing the curriculum}

Saudi educators would have to shift their beliefs and practices to see the children as "authors of their own learning" (Malaguzzi1994, 55) and "the curriculum makers" (Firlik 1996, 220). When I asked participants about the children's role, most answered that it depended on the activities occurring in each period of the daily schedule. S.MT. spoke to this point: "The child is usually a recipient of learning. But with a creative teacher, they will be a participant" (personal communication, December 12, 2017).Dang $(2011,36)$ reported that in REA kindergartens, teachers and children "felt more powerful, confident, creative, open-minded, and interrelated." This is what Saudi ECE administrators have said and written is their goal.

\section{Children's learning development can be assessed meaningfully}

In Saudi kindergartens, children are assessed in many ways: a checklist assessment upon completing each learning unit; an oral daily assessment at the conclusion of each lesson; the end of the year assessment to see how well all goals were met; and an electronic assessment in the Noor system, a mandatory measurement tool used in all kindergartens in the country. M.K, a teacher at a private kindergarten, quickly responded to my question about the nature of the Noor assessment system: "We use the Noor system at the end of each unit to assess the children. It has from 190 to 250 points according to each unit's assessment criteria. It's required by the ministry. It's hard for teachers if you have twenty children and you have to assess them every two weeks. . It's very exhausting" (M.K., personal communication, December 12, 2017).Most respondents agreed that assessments obtained by the Noor system were not accurate or objective.

In the view of RE philosophy, comparing each child to a national set of Saudi children according to criteria formulated by educators at the Ministry of Education does not create a valid measure of the child's development, the effectiveness of the curriculum, or the competence of the teacher. However, documenting what the child does and says can track their psychosocial development, and teachers can use this documentation over the course of three years to explore the student's interests and engage in meaningful conversations about their learning.

\section{Expressions of learning that suit the religion and culture of $S A$}

Because Islam is central to Saudi culture, educators must incorporate religious and moral values, religious holidays, and religious stories and characters in the curriculum (Knaan 2004; Omair 2013).However, the REA is flexible and malleable, and has been successful in some kindergartens in Kuwait, a culture with similar religious beliefs and values (Alhashel 2012; KUNA 2012).For instance, dancing and music are not approved in public education because it conflicts with the people's religious beliefs. However, it is feasible to provide children with a variety of materials and tools to express their learning within the framework of Islam while still embracing RE principles.

\section{Empower teachers to collaborate with children to design projects}

This power will reflect greater trust in ECE teachers. Project facilitation requires teachers to closely observe what the children are doing, listen to what they say, accept children as they are, and focus on what they know (Glover and Keene 2015).Some public and private kindergarten teachers I interviewed occasionally found opportunities for these kinds of lively interactions to occur and seemed excited to talk about them. The responses I received indicated misunderstanding or lack of agreement among the respondents about whether the national ECE curriculum was designed according to children's interests. When asked about her previous teaching experience while we were discussing the child's role in planning or suggesting a learning activity or topic, an administrator stated: "When I planned for the unit activities, I asked the children: What do you want to learn about tomorrow, or next week? I listened to their answers and built my lesson plans from their ideas" (T.M., personal communication, August 15, 2017). This administrator's statement is a clear example that some kindergarten teachers do find, and have for some time found, ways to work around the standardized curriculum. Such attitudes may proliferate if given an opportunity to experiment with the REA in their classrooms.

\section{Teachers and supervisors should refocus on the children}

Kindergarten teachers in SA spend a lot of time preparing the classroom for activities, planning units and lessons, and also completing paperwork, marking assessments, and other bureaucratic tasks. They should have more time to observe and offer support to students as they engage in learning activities. An administrator talked about how she manages to address the children's needs within the planned lessons: "If we had a child and his mother was giving birth and he had new brother and sister, and the teacher felt that the child wanted to talk about this new situation ... she will discuss this with the class during free-play time or the final meeting. It does not have to be in the circle time" (S.AO., personal communication, August 15, 2017). These ECE educators try to find connections to the 
children's current interests so as to increase their active involvement and participation, after they gain the principal's permission to do so. In practice, Saudi ECE teachers comply with the standardized curriculum topics but often vary teaching methods, enrich the classroom environment, and renew the children's engagement in lesson activities.

\section{Redesign existing kindergartens or transfer to better buildings}

In the REA, the physical environment is designed for and with the children, and all resources and spaces should serve their learning and exploration.

The recent push by the Ministry of Education to build more private kindergartens through private investment opens the possibility for the construction of a model RE school, or one designed with RE principles in mind. The rented buildings that have become functional kindergartens are an issue that was mentioned by the majority of interviewees, particularly when I asked what challenges confront Saudi ECE. One administrator said, "We need buildings with standards that are specified for kindergarten children and keep up with the quantitative expansion. We have a deficiency there currently and a large number of children in need of kindergarten placement in a system that does not have enough room for them all" (S.MH., personal communication, August 16, 2017).

\section{Educators should rethink the daily schedule}

According to Lewin-Benham (2011), "activities that change every twenty or thirty minutes break children's focus" (62). In the near term, the ministry could redesign the daily classroom schedule so that children have more time for free exploration, investigation, and play outside the direct control of the teacher or the standardized curriculum.

\section{Begin to change the volunteering orientation of Saudi society}

Many Saudis seem to think that education is a government responsibility, not the community's (Metwaly and AlSaud 2012). Families and the larger community needs to see volunteering for schools as supporting a vital ingredient for the health and welfare of society - the education of the young. My interview with administrator E.A. raised an interesting perspective about volunteering in SA. She told me that volunteering is considered a new cultural phenomenon and currently seems focused on religious purposes. She gave an example: "Volunteering is new. For example, if I have money and I want to make a donation, why would I want to donate to the Ministry [of Education] to build schools? It is better if I build a mosque or donate to the poor. It means that our volunteerism in SA is confined in one aspect only [i.e., religion]" (E.A., personal communication, August 20, 2017). One of Vision 2030's aims is expanding volunteerism in more sectors of Saudi society, not only in the religious arena.

\section{Role of RE advocates}

Saudi educators who advocate the adoption of the RE philosophy in ECE need to understand that establishing such a different educational culture takes time, hard work, and collaborative efforts from all parties involved.The root of it all is firmly believing in the children, believing they want to learn and will learn more effectively if educators do not erect too many obstacles in their path. That will be the first big leap that Saudi ECE must take - a reorientation of the view of the young child as an active, responsible learner. Most of the participants were optimistically positive about the possibility of its implementation. However, this optimism was often accompanied by a but or an if. Following are samples of the participants' responses to my question: Do you think it is possible to implement the REA in SA's kindergartens? "[It is] possible. Why not?" (T.M., personal communication, August 15, 2017); "We need an approach like this. We need to do something, a revamping that advances our curriculum" (K.A., personal communication, December 17, 2017); "I support such diversification and renewal, as long as it suits our culture and it conforms to the national child development standards" (S.MH., personal communication, August 16, 2017); "[Yes, if it is] appropriate and it will suit us and our needs in SA. There is currently a greater chance of adopting the REA than ever before because the long-standing social obstacles are decreasing of late, and there is more flexibility and freedom now" (E.A., personal communication, August 20, 2017).

\section{Concrete Suggestions for REA Implementation}

I offer educators, especially those at the Ministry of Education, three possibilities for an initial RE implementation.

1. Add some core REA practices to the current self-learning curriculum. This suggestion matches the experience of China and Vietnam where RE-inspired kindergartens included "the project approach and parent participation" (Dang 2011, 38). Afterward, teachers felt the revised curriculum enhanced parental involvement and empowered teachers (2011). Moreover, in early 2018, the Saudi Ministry of Education released a new policy for public education, including ECE, which aims to add four hours per week for extra-curricular activities. This presents an opportunity to bring REA project-based learning and improved teacher documentation processes to the self-learning curriculum.

2. Find an investor(s) who is interested in establishing a RE kindergarten. This will also enhance the involvement of the private sector in the development process to achieve Saudi Vision 2030 (Mosaad 2016; 
Patalong 2017). For instance, Al-Riyadh school started to adopt the REA in their kindergarten two years ago. They implemented the REA in four classes and the next year (2017/2018) they implemented it in all classes. This is evidence that the private sector is ready to accept adopting new educational philosophies and approaches.

3. Implement the REA in one or two public kindergartens from three or four educational districts in Riyadh. The classrooms should be large and open, have lots of rich learning materials and resources, a supportive and sympathetic principal, and a sufficient number of RE-trained ECE teachers.

\section{Conclusion}

The Saudi Ministry of Education is currently reviewing ECE as part of Vision 2030, looking to upgrade the curriculum and investigating ECE policies and practices in other countries. In April 2018, the ministry hosted Claudia Giudici, president of Reggio Children, to speak about the REA at a live YouTube forum broadcast. It was part of the 6th International Education Forum and Exhibition 2018 and was titled "Teaching and Learning in Early Childhood Education" (Tatweerfor Educational Services, 2015/2016). At the very least, education policymakers seem interested in change and open to new approaches in ECE. The next step might be to sponsor visits by teachers, supervisors, and other stakeholders to RE centers in Italy or elsewhere, and to attend professional RE conferences. These outreach efforts provide chances to communicate with other educators from different countries and incorporate their experiences in implementing the REA in their local contexts. Educators from the United States, Kuwait, and South Africa did much the same thing when they began investigating the REA (Aljafarand Alomar 2010; Browne and Hugo 2014; Kang 2007).

While adoption of any comprehensive education reform is difficult, lengthy, and sometimes expensive, the rewards can be substantial. It is encouraging that many recent signs indicate Saudi ECE, along with all of Saudi public education, is interested in reform, making plans and creating new policies to improve ECE. In interviews, I repeatedly heard an openness to change from teachers, supervisors, and administrators alike. One response stands out from one of the district supervisors I interviewed:

I encourage you to achieve this. I hope . . . you circulate your [study] in the Ministry of Education. Do not quit. ... It takes patience even to apply your study as an experiment. . . . The ministry welcomes new experiences and useful reforms that are built on valid foundations. (N.J., December 16, 2017)

\section{References}

Alageel, A. 2005. Education Policy in Saudi Arabia. Riyadh, Saudi Arabia: Alrushd.

Aldham, L. 2012. "Some of the Educational Supervision Problems in Public Kindergartens in Riyadh" (Master's Thesis). Alemam University, Riyadh, Saudi Arabia.

Alhamed, A., andM. Zyadh. 2007. Education in the Kingdom of Saudi Arabia. Riyadh, Saudi Arabia: Alrushd.

Alhashel, N. 2012. "Report about the international conference regarding the Reggio Emilia educational approach for preschools and kindergartens".[In Arabic.]Arab Children Journal 51: 89-100.

Aljafar, A., andB. Alomar. 2010. "Report on visiting the Reggio Emilia group".[In Arabic.]ArabChildren Journal 43: 121-122.

Aljabreen, H., and M. Lash. 2016. "Preschool education in Saudi Arabia: past, present, and future". Childhood Education92(4): 311-319.

Al-Madkhaly, M. 2014. "The educational role of kindergartens in Saudi Arabia". [In Arabic.]International Education Specialist Journal 3(8): 113-129.

Alnageeb, E. 2009. “The modern educational trends in teaching Kindergarten's child: The Reggio Emilia experience in Italy".[In Arabic.]Arab Children Journal 52: 83-143.

Alotaibi, M. 2008. Early Childhood Education Development Project in Members of the Arab Bureau of Education for the Gulf States. Riyadh, Saudi Arabia.

Alotaibi, M., and B.Alswilem. 2002. "Kindergartens' objectives in Saudi Arabia: analytic study".[In Arabic.]Educational Research center, Collage of Education, King Saud University, Riyadh, Saudi Arabia.

Alsedrani, G. 2018. "Reforming Saudi Early Childhood Education: Saudi Educators' Perspectives on the Reggio Emilia Approach" (PhD Dissertation). University of Rochester, Rochester, NY, USA.

Alshawareb, A. 2012. "Science experiences in kindergartens from Reggio Emilia approach's perspective".[In Arabic.]Arab Children Journal 52: 69-81.

Bakari, M. 2012. "The Difficulties that Face the Female Educational Supervisors in Applyingthe Methods of Educational Supervision in Kindergarten, from the Perspective of Female Educational Supervisors and Teachers at Holly Makkahand Jeddah" (Master Thesis). Umm Alqura University, Makkah, Saudi Arabia.

Bamberg, M. 2010. Narrative Analysis. In H. Cooper (Editor-in-chief), APA handbook ofresearch methods in psychology. Washington, DC: APA Press.

Browne, T., and D. Hugo. 2014. "Reflections and research on Reggio-inspired rights and practice in South Africa". Innovations in Early Education: 10-17.http://www.reggio.co.za 
Cagliari, P., M. Castagnetti, C. Giudici, C. Rinaldi, V. Vecchi, and P. Moss. 2016. LorisMalaguzzi and the School of Reggio Emilia. NY: Routledge.

Creswell, J. 2013. Qualitative Inquiry \& Research Design: Choosing AmongFive Approaches. Thousand Oaks, California: SAGE.

Dang, T. 2011. An Exploration of Reggio Emilia-Inspired Practice in China and Vietnam - a Meaning Making Process. Ann Arbor, MI: ProQuest LLC.

Dodd-Nufrio, A. 2011. "Reggio Emilia, Maria Montessori, and John Dewey: Dispelling teachers' misconception and understanding theoretical foundations". Early Childhood Education Journal 39: 235-237.

Eckhoff, A., and M. Spearman. March 2009. "Rethink, reimagine, reinvent". Art Education62(2): 10-16.

Edwards, C. P., N. Gandini, and G. Forman. 2012. The Hundred Languages of Children.California: PRAEGER.

Firlik, R. 1994. "Promoting development through constructing appropriate environments:Preschools in Reggio Emilia, Italy". Day Care and Early Education 22(1): 12-20.

Firlik, R. 1996. "Can we adapt the philosophies and practices of Reggio Emilia, Italy, for use inAmerican schools?". Early Childhood Education Journal 23(4): 217-220.

Gandini, L. 1993. "Fundamentals of the Reggio Emilia approach to early childhood education". Young Children 49(1): 4-8.

Glover, M. and E. Keene. 2015. The Teacher you want to be: Essays about Children, Learning, and Teaching. Portsmouth, NH: Heinemann.

Hewett, V. 2001. "Examining the Reggio Emilia approach to early childhood education". Early Childhood Education 29(2): 95-100.

Hwasheen, Z., and M.Hwasheen. 2008. Recent Trends in Child Education. Aman, Jordan: Dar Alfiker.

Inan, H. 2009. "Science education in preschool: how to assimilate the Reggio Emilia in a Turkish preschool". Asian-Pacific Forum on Science learning and Teaching 10(2): $\quad$ 5-15.

Kang, J. 2007. "How many languages can Reggio children speak? Many more than a hundred!".Gifted Child Today 30(3): 45-65.

Knaan, A. 2004. The Education Role in Facing Globalization and the Challenges of the 21st Century and Enhance Identity and Belonging to the Nation. Research Presented at the Globalization and Education Priorities Seminar. Riyadh, Saudi Arabia: King Saud University.

Lewin-Benham, A. 2011. Twelve Best Practices for Early Childhood Education. New York, USA: Teachers College Press.

Lindsay, G. 2015. "Reflections in the mirror of Reggio Emilia's Soul: John Dewey's foundational influence on pedagogy in the Italian educational project". Early Childhood Education 43: 447-457.

Malaguzzi, L. 1993. "History, Ideas, and Basic Philosophy". InThe Hundred Language of Children: The Reggio Emilia Approach to Early Childhood Education, edited by C. Edwards, L. Gandini, and G. Forman (Eds.), 41-89. Norwood, NJ: Ablex.

Malaguzzi, L. 1994. "Your image of the child: Where teaching begins". Child Care Information Exchange 96: 5261.

Metwali, N. 2007. Education in the Kingdom of Saudi Arabia. Riyadh, Saudi Arabia: Alrushd.

Metwally, M., and A.Alsaud. 2012. Childhood Organizations and Policies. Riyadh, SaudiArabia: Qurtoba.

Mossad, K. May 2016. "How Will Saudi Arabia Revamp its Education System?" https://www.fairobserver.com/region/middle_east_north_africa/will-saudi-arabia-revamp-educationsystem-11082/

Nelson, R. 2000. "Application of the Reggio Emilia Approach to Environments in the United States: A Case Study" (Doctoral dissertation). The Graduate Collage at the University of Nebraska, Lincoln, Nebraska, USA.

New, R. 2009. "Reggio Emilia as cultural activity theory in practice". Theory intoPractice46(1): 5-13. doi: $10.1080 / 00405840709336543$

Omair, G. 2013. "The reality of Montessori Educational Curriculum Application in theKindergarten from the Supervisors and Teachers Point of View in Riyadh City"(Master's Thesis). King Saud University, Riyadh, Saudi Arabia.

Palestis, E. 1994. "Lessons from Reggio Emilia”. Principal 73(5): 16-19.

Patalong, P. 2017. "Vision 2030 and the Transformation of Education in Saudi Arabia: One Year on". https://www.tamimi.com/law-update-articles/vision-2030-and-the-transformation-of-education-in-saudiarabia/

Piaget, J. 1973. To Understand is to Invent: The Future of Education. NY: Grossman Publishers.

Rinaldi, C. 1994. "Staff development in Reggio Emilia”.ERIC Digest, PS 022934, University of Illinois, Urbana, IL.

Saudi Ministry of Education. 2005/2006. Teachers' Guide for Self-Learning Curriculum in Kindergartens. Riyadh, Saudi Arabia: Educational development Center. 
Saudi Vision 2030. 2016. Media Center and Documents “Saudi Vision 2030”.http://vision2030.gov.sa/en/mediacenter

Staley, L. 1998. "Beginning to implement the Reggio philosophy”. Young Children 53(5): 20-25.

Strong-Wilson, T., and J. Ellis. 2009. “Children and place: Reggio Emilia's environment as third Teacher”. Theory into Practice 46(1): 40-47.

Tarr, P. 2004. "Consider the walls". Young Children 59(3): 88-92.

Tatweer Company for Education Services. 2015/2016. The Organizational and Procedural Guide for Kindergartens and Nurseries. Saudi Ministry of Education.

https://departments.moe.gov.sa/EducationAgency/RelatedDepartments/Kindergarten/Documents/الـ دل

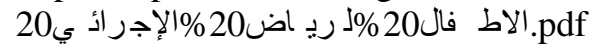

Valentine, M. 2006. The Reggio Emilia Approach to Early Years Education. NorthLanarkshire, Scotland: Scottish Consultative Council on the Curriculum.

Wurm, J. 2005. Working in the Reggio Way. Paul, MN: Redleaf Press. 